Sylvain R. Duc

Klaus U. Wentz

Kurt P. Käch

Christoph L. Zollikofer

\title{
First report of an accessory popliteal muscle: detection with MRI
}

Published online: 10 August 2004

(C) ISS 2004

The online version of the original article can be found at http:// dx.doi.org/10.1007/s00256-004-0775-9

S. R. Duc · K. U. Wentz ( ) C. L. Zollikofer

MR Research Group of the Institute of Diagnostic Radiology, Kantonsspital Winterthur,

Brauerstrasse 15, 8401 Winterthur, Switzerland e-mail: Ku.wentz@ksw.ch

Tel.: +41-52-2664610

Fax: +41-52-2664603

K. P. Käch

Department of Trauma Surgery,

Kantonsspital Winterthur, Winterthur, Switzerland

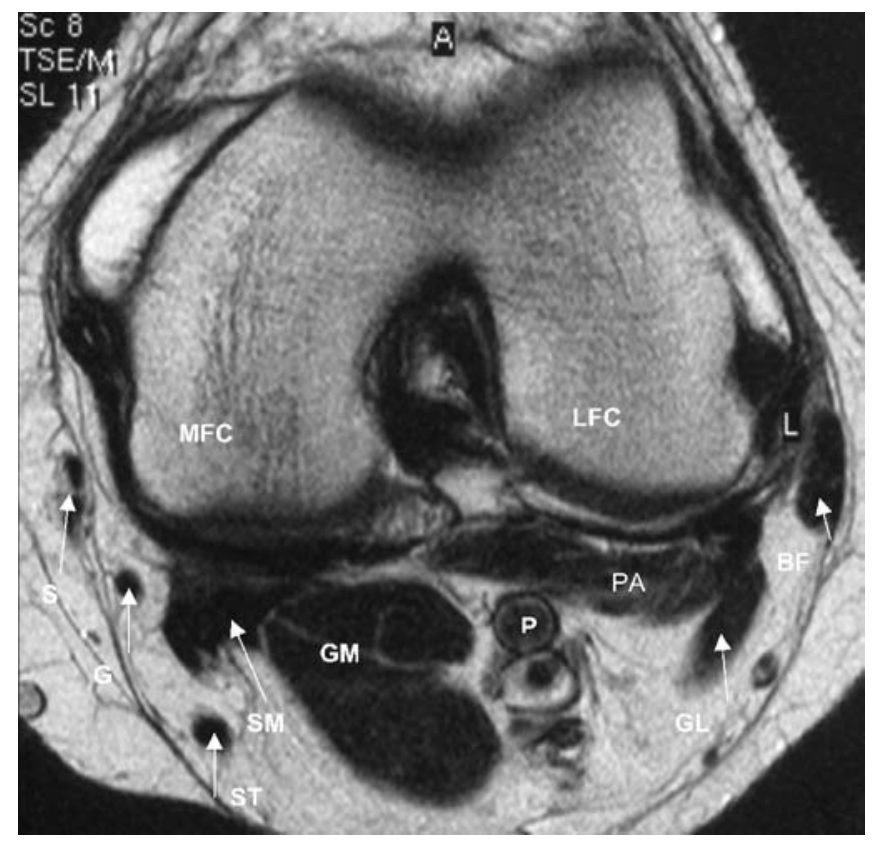

Fig. 1 Axial image shows the location of the accessory popliteus muscle deep in the popliteal fossa, passing between the posterior articular capsule and the popliteal artery

\section{Skeletal Radiol (2004) 33:429-431}

The following abbreviations, which were found in Figures 1 and 3 were previously undefined:

$B F$ Biceps femoris, $F e$ Femur, FI Fibula, $G$ Gracilis, $G M$ Gastrocnemius medialis, $G L$ gastrocnemius lateralis, $L F C$ Lateral femoral condyle, MFC Medial femoral condyle, MTP Medial tibial plateau, $P$ Popliteal artery, $P A$ Popliteus accessorius, Pop Popliteus, $S$ Sartorius, SM Semimembranosus, ST Semitendinosus, TI Tibia

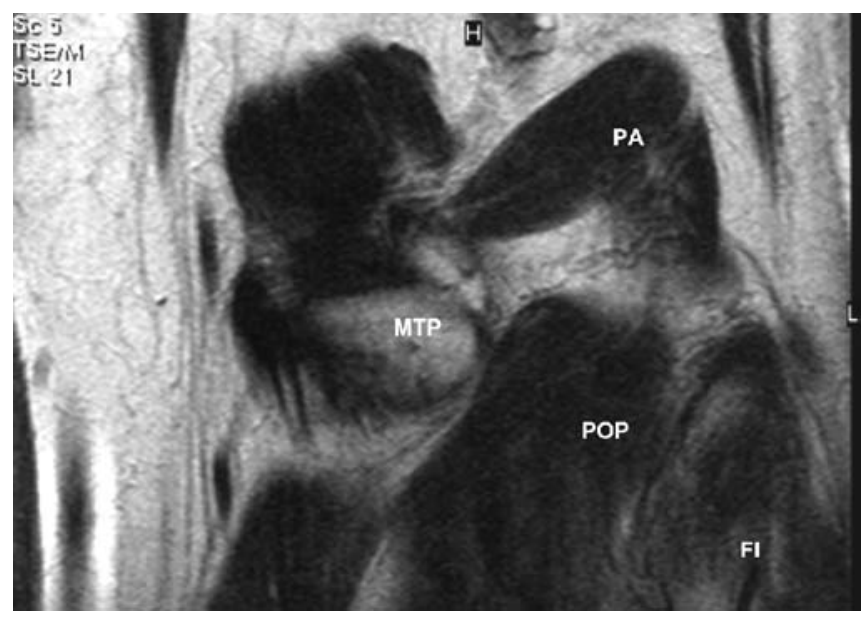

Fig. 3 Coronal image nicely shows the oblique descending course of the accessory popliteal muscle from the lateral femoral condyle towards the medial femorotibial compartment 